\title{
Professional training at the university and digitalization of education: problems and prospects
}

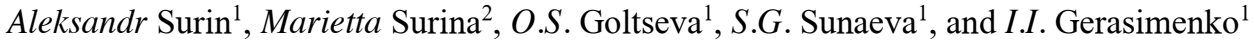 \\ ${ }^{1}$ K.G. Razumovsky Moscow State University of Technologies and Management, 73 Zemlyanoy Val, \\ 109004 Moscow, Russia \\ ${ }^{2}$ Don State Technical University, 1 Gagarina Street, 344000 Rostov-on-Don, Russia
}

\begin{abstract}
The article deals with the specifics of training specialists in creative professions (designers, architects) at the university and the general psychological and pedagogical conditions for the formation of specialized consciousness. The purpose and main objective of the study are to identify those conditions for the introduction of digital learning that enables to get a really stable positive result and create a basis for the effective application of electronic equipment and digital education methods. In this context, we study the psychological features of the formation of professional thinking and teaching methods of professional activity at the university level. The psychological conditions of the translation of visual and verbal information into the mental plane, the ways of transformation of students' learning activities and their formation as creative specialists are considered. The basic and special abilities in the field of color proficiency are revealed. The article examines the problematic and promising aspects of digitalization of education in the framework of design education. The ways of effective integration of digital education and traditional forms of professional training in the training of specialists in creative professions (designers, architects, artists, etc.) are determined.
\end{abstract}

\section{Introduction}

Currently, the issue of mass digitalization of education is being forced. It is noteworthy that the universal introduction of digital technology creates the illusion of a "panacea" that can instantly improve the quality of education and training. However, the period of forced distance education during the pandemic showed that the complete transfer of "contact" training (direct interaction of the student with the professor) to the distance format gave serious failures and revealed a number of problems that need to be addressed.

At the level of higher education, during the period of universal distance learning in 2020 , there was a decrease in the level of training of students and the sharp load increase on teachers, who had to literally record every action. The preliminary analysis of this situation shows that the decline in the quality of students' training occurred as a result of the formalization of the educational process, the transformation of the professor's teaching function into a controlling one by increasing the share of verbal control, which led, in fact, to the emasculation of the content of education. Verbal control (testing, control questions) 
involves memory to a greater extent (more often short-term memory), but it does not teach the mental activity, does not contribute to the development of imagination, creative (or abstract-logical) thinking, which is the essence of education. The introduction of universal electronic visualization of information (presentations) somewhat facilitates the development of educational material, but, in general, it turned out to be ineffective. The question arises - what is the reason? Back in the twentieth century, a number of foreign and domestic scientists who studied the mechanisms and psychophysiology of visual perception revealed the complexity of this process. It turned out that vision (perceptual activity) is closely related to thinking, the role of the connecting link between them is performed by sensory perception $[1,2,3,4,5]$. It is characteristic that, in training, the visual image does not automatically turn into a conceptual one since the student shall perform a certain algorithm of actions in the external plane $[6,7,8,9]$. This aspect will be discussed in more detail below.

\section{Materials and Methods}

The issue of equipping universities and schools with electronic equipment is very important, but it requires careful consideration and study of all those aspects that emerged during the forced mass distance learning. The purpose of this study is to identify those conditions for the introduction of digital learning that enables to get a really stable positive result and create a basis for the effective application of electronic equipment and digital education methods. We will try to consider some of the current issues of education at the university on the example of creative professions (design, architecture, art, etc.) and determine the conditions for the application of digital education.

The methodology of the research of the set problems will be based on the activity approach in the training of professional activity. The study and identification of the principles of training in higher education is based on the methods of analysing the scientific research in the field of pedagogical psychology and the method of pedagogical generalizations and modeling. The outlined above training for creative professions at universities, to a greater extent than in other specializations (exact sciences, engineering and technical professions), is based on the principles of visualization and creativity, but the problems of the education quality still remain. The hypothesis of the scientific research is based on the fact that the effectiveness of the application of digital learning in the process of higher education for creative specializations directly depends on the degree of formation of basic structures of professional thinking, the formation of which, in turn, goes in parallel with the formation of the student's professional vision. We will proceed from the fact that the higher education is aimed at forming a professional way of thinking and, ultimately, raising the consciousness of the future specialist to a new, higher level. Consequently, the tasks of the educational process are related to the training of mental methods of activity [10], characteristic of a particular specialization, which, in fact, is expressed in the formation of a certain type of student's competence. It would seem that in this case, the application of digital technologies in the training of a designer or architect will best solve these problems and quickly achieve the goal, but this does not happen. If we go back to the research of Russian scientists of the late twentieth century, who were very actively engaged in the psychology of learning, we will see that the preparation for professional activity when studying at a university is associated with a number of psychological factors that cannot be ignored in our time.

It should be noted that due to the research of Russian psychologists (V.V. Davydov, A.N. Leontiev, V.P. Zinchenko, P.Ya. Galperin, N.N. Nechaev, N.F. Talyzina, etc.), school and university education at the end of the twentieth century began to actively develop and give a steady effect. At the end of the 80-90s, a number of interesting scientific 
achievements were reached, and the activities of many school teachers and professors of higher education were creative and innovative. Not only our teachers but also foreign specialists showed interest in scientific research in the field of learning psychology. In particular, Japanese specialists carefully studied and adopted the scientific achievements of the late twentieth century, made on the basis of the Faculty of Psychology of the Lomonosov Moscow State University. We would like to draw the attention of modern professors to the scientific heritage that has already been accumulated in our country and has not lost its relevance, since it affects the deep foundations of the human psyche and is associated with the laws of the psychology of learning a particular type of activity.

\section{Results and Discussion}

The studies of the role of visual images in learning conducted in the twentieth century by Russian psychologists showed that material activity is closely related to mental activity. Moreover, the success of the activity of both the student and the specialist depends on the degree of formation of spatial representations and goes through the interaction of sensory and mental components. If such ideas are not formed in the student, then visibility (visual image) is not an effective method of teaching [5, 9, 11, 12]. Russian psychologist V.V. Davydov distinguished two types of concepts - theoretical and empirical. Having studied the features of their formation in the processes of development and learning, he found that the source of the theoretical concept is not the direct perception of the discipline but the form of "connection" of perception and representation images set by a certain way of human activity. If this mode of activity is not formed in a person, then the processing of sensory data is carried out in the form of general representations, regardless of their type ("visual" or "abstract") [6].

The principle of the student's activity in translating visual-verbal information into conceptual-figurative (internal plane) was revealed in the papers by A.N. Leontiev and V.P. Zinchenko [5, 7, 9]. The mechanism of transition from external action to internal action (outlined by L.V. Vygotsky) [11] was studied in detail and disclosed in the theory of the gradual formation of mental actions and concepts of P.Ya. Galperin $[8,12]$. As a result of the experiment, P.Ya. Galperin established the special role and significance of the material form of action (external action with an object) in the learning process. It was shown that the sensory picture of an object or situation hides the main scheme ("operational scheme"), which expresses their function in the actual task, so it is not the objects themselves and their "personal" signs that are important but the function that they perform [12]. Moreover, to accumulate knowledge, the student shall carry out his/her own activities to transform the original discipline situation. In this case, the effectiveness of training in the accumulation of new knowledge is associated with the stage of "materialization" of mental actions (operating with diagrams, signs, graphic images), since the transition of an action with real objects to speech is associated with a significant transformation of the action itself $[8,12]$.

In the research by N.N. Nechaev, it was proved that transformations are not fixed in real action since it is necessary to build a "model" (scheme) that records all the stages of transformation (i.e., modeling stage). In this case, modeling in the student's educational activity is a cognitive and creative process based on the student's activity. In other words, theoretical activity in the educational process can successfully proceed only if it finds its embodiment in various kinds of material forms (from a sign, a symbol to an object), where the model acts as a link between the idea and its material embodiment $[13,14]$. The abovementioned studies also allowed us to identify the actual form of the relationship between sensory images and concepts (as their abstract images, abstractions) used by a specialist. The role of the link between the perceptual perception and the conceptual component of thinking is performed by "operational schemes", which are a system of folded and 
automated operational intellectual actions. In the educational activity of the student, the sensory image is transformed into a conceptual one only in the case of the deployment of the "operational scheme", the carrier of which it is, and its application by students through the implementation of their own activities, which initially take place in the external plane in the form of a material (materialized) action. Thus, the transformation of the sensory image into the conceptual one is carried out through the student's activity (and not "listening", observation, and contemplation), which should begin with the material stage and is built based on "operational schemes of thinking " (definition by P.Ya. Galperin) [12], characteristic of this type of professional activity. In this case, the formed conceptual image leads to a change in the primary image, resulting in a change in the student's "vision" of reality and setting it up for professional perception $[10,12,13]$.

At the initial stages of studying at the university, everything is new for the student: object of study, conceptual framework, technical skills and techniques, and way of thinking and "seeing" reality. The formation of the conceptual basis is based on the development of professional thinking methods. When learning is organized through a material (materialized) action and the construction of a discipline-specific model, then the action results in highlighting the essential features, which become "visible" to the student and are fixed in the model. The model becomes visual $[10,13]$. In this case, the student's activity is aimed at creating a material analog of the concept (system of concepts), which is the foundation of the matrix of the conceptual basis of consciousness. The concept is memorized in the form of an abstract image, and the object's characteristics become "visible" to the student. The stage that ensures the students' independent activity in analyzing the information encoded in a certain sign system is also important. As a result of mastering the content of this information, professional ideas, thinking and vision of reality are formed $[9,10,12,13]$.

Another point is related to the allocation of general and special abilities that are characteristic of this type of activity. The formation of any type of special abilities is based on the need to identify their "invariant" (permanent core as their psychological basis), which is associated with the identification of characteristic skills in the activities of various specialists $[13,14,15]$. This aspect is associated with the identification of features that are characteristic of the manifestation of special abilities, for example, such as the ability to master color by designers, artists, or architects. The general skills include: ability to differentially perceive individual conceptual characteristics; ability to holistically perceive and display in a visual image the totality of characteristics of the object. The definition of the psychological invariant of special abilities is also associated with the identification of characteristic skills in the activities of specialists in creative professions. In the work of professional designers working with color, such skills should provide them with the ability to analyze the color form. These include:

- ability to create color harmony on the plane following the developed socio-cultural ideas about the principle of harmony formation;

- ability to select and organize the color code based on the specified conditions;

- ability to transform color harmony and create a new set of color modulations depending on the desired content;

- ability to perform color diagnostics and psychological selection of colors following the type of task, etc. [15].

It should be emphasized that the basis of the ability to master color is made up of intellectual abilities that provide action with the object of activity, and a system of professional concepts that define the way of coloristic "vision" of reality. (The object of activity is understood as the subject of study - this is the concept, representation, methods of activity, visible object, etc.). The stage that ensures the students' independent activity in analyzing the information encoded in a certain sign system is important. As a result of 
mastering the content of this information, professional ideas, thinking and vision of reality are formed. Both sides of the activity (ability to think in terms and "see" the subject from a professional point of view), as we have already noted above, are associated with the creative and conceptual components of professional thinking. This type of components is a process of transformation of the primary (perceptual) image into an abstract (conceptual) one by modifying it and plays a leading role in the processes of formation of the professional consciousness of students.

Thus, modern studies in the field of pedagogy and psychology allow us to identify the following didactic conditions necessary for the formation of professional thinking and color skills during specialized training. These include:

- organization of the process of forming the creative and conceptual components of professional thinking of the designer (architect, artist) based on teaching students the means and methods of professional activity;

- formation of the conceptual apparatus through a system of conditionally schematized images that reflect the main content of basic concepts in a certain area (coloristic, artistic, design, etc.);

- curtailment of mental actions and automation of the process of working with professional concepts in the field of color by working out the speed of obtaining a creative solution;

- overcoming the acquired knowledge through a creative solution of educational tasks (identification of a stereotypical image, its conscious destruction, and transformation).

Technical skills of working with pictorial materials are an external manifestation of intellectual skills, which are the psychological basis of the ability to master color. They act as an external tool for students' actions with an object (concept, image, representation, etc.), providing a material embodiment of the content of concepts when translating knowledge from the external to the internal plane (and vice versa), and reflecting the way of thinking (activity) when translating knowledge already accumulated by students from the internal to the external plane (picture, layout, project, etc.).

The level of development of abilities to master the color is determined based on the precision of creative expression of the content of professional concepts using the relevant academic discipline with the choice of adequate methods and techniques; ability of students to create the necessary color harmony and color image following the content of the task; ability to freely apply color when performing project tasks within various academic disciplines $[15 ; 16]$.

An important condition in the process of studying creative specializations at the university is a situation when the student's educational activity acquires a creative character. For such a transformation to occur, it is necessary to create situations of "contradiction" between the task set and the available capabilities of the student. The interaction between the student and his practical experience ("situation of contradiction") leads to the fact that there is a change in the way of his activity, and the actual activity of the student becomes creative $[9 ; 14 ; 15]$. Therefore, teaching creative professions should be aimed not just at creative results, but at the process of mastering the ways and methods of specialized thinking by students, as a result of which educational activities transform and their consciousness reaches a new, professional level. Thus, the study of the way of thinking is primary in the professional training but should go in parallel with the acquisition of technical techniques and skills, most of which are now associated with the development of computer technologies. In this case, the learning process is significantly accelerated and leads to a significant reduction in hours and efforts of professors spent on the formation and development of the technique, i.e., the psychological restructuring of the student's consciousness in a professional way. 
One should not fall into a state of increased euphoria from the abundance of digital technology and software. Technical means and computer programs facilitate and accelerate those processes in learning that are associated with correction, replication and variability (ideas, texts, etc.), but cannot form creative activities related to the generation and originality of ideas, as well as form actions of a sensory-mental nature (sense of space, composition, rhythm, harmony, etc.) based on the material action with the object of study. For example, modern training of graphic designers is associated with the knowledge and study of a line of specialized programs (Adobe Photoshop, Adobe InDesign, Adobe Illustrator, Adobe After Effects, etc.), the acquisition of which is necessary for working in professional enterprises (design studios, architectural design workshops, printing houses, etc.). However, technical knowledge of different programs does not provide the professional competence of a specialist in the field of design. The design of a product layout (project, book, magazine, website, packaging, banner, etc.) is based on the knowledge formed in practical classes in painting, drawing, composition, design, color science, etc. In these classes, with direct contact with the professor, students develop basic knowledge, skills and abilities to work with the object, develop the necessary sensory and immanent senses (harmony of color, balance, rhythm, etc.), form a professional way of thinking, and develop a number of psychological characteristics (competencies) $[15 ; 16]$. These classes are important since they provide (with the right approach) the process of interiorization (L.V. Vygotsky) of mental actions, that is, the translation of external material action into internal mental action [11], which allows creating a psychological basis for the formation of a professional way of thinking. In addition, practical classes promote the development of imagination, creative thinking and professional "vision" of the object of activity $[15 ; 16 ; 17]$.

Currently, digital education is aimed at studying those computer programs that are associated with technical skills of modeling in virtual space and working in graphic editors. It is based on the concepts, mental skills, and psychological structures that are formed in students during full-time practical classes. Thus, digital education implies that the student already has a certain level of training and a culture of thinking. In turn, this approach reinforces the importance of practical classes and requires their organization, aimed at mastering the ways of thinking and methods of professional activity. In this case, it is important to take into account the psychological and pedagogical features of teaching a certain type of activity, to be able to model the ways of professional thinking and find adequate forms of their development (corresponding to the language of this type of activity) through the student's activities. Therefore, at the initial stages of professional training at the university, during the formation of students' conceptual basis of thinking and professional "vision", it is more efficient to master computer technologies in specialized disciplines (computer science, computer technology) without overloading with a creative component. When a student just starts studying computer programs, he does not yet understand and "does not see" where to look on the monitor screen and what to do. Specialized disciplines are best aimed at introducing students to the technical aspects of working in basic computer programs (CorelDRAW, Microsoft Word, Microsoft PowerPoint, etc.) and do not require creative solutions. At the second stage, when training in specialized disciplines begins, digital technologies can flow into the leading profile disciplines (design, book graphics, typography, photography) but not dominate them. It is important to start the stage associated with the development of an idea and the search for a creative solution with "manual sketching" (sketches, brief sketches). Computer technologies (in this case, the Internet) help to start the thinking process by selecting analogs and prototypes. The creative process is activated at the moment of sketching, which is an external, materialized form of imagination activity, and the "manual submission" of sketches significantly speeds up and facilitates the search for ideas, since it is not associated with technical actions in specialized 
computer programs (which the student still has a poor command of). This approach provides a rapid and correct formation of a professional way of thinking, assimilation of new specialized knowledge, and development of professional skills and abilities.

At a higher (professional) level, the connection of material activity with mental activity is manifested in the automation, "folding" of mental and motorial processes, and the development of dynamic spatial representations [10, 12, 15]. In this case, many actions, especially technical ones, are performed automatically by a specialist at the subconscious level, and the consciousness is actualized on the search for creative solutions. Thus, as a result of the materialization of mental actions (process of interiorization) and development of professional ways of thinking (operational schemes of thinking), the student develops a professional "vision" of reality, changes the consciousness, and raises it to a new, higher level. Professional "vision" is a mental process that still needs to be "formalized", formed and "launched" in the student's head, so it requires a separate stage of training [15]. Only the professor can ensure the success of this process, and as a result of mutual communication with the student.

It can also be noted that the period of long-term universal distance education has also had a negative impact on school education. Firstly, there was a deterioration in the physical health of students, decrease in vision, and development of myopia (at the level of secondary and higher school). Secondly, at the school level, such aspects as the overload of the nervous system of pupils were revealed, as a result of which many pupils had mental health disorders. Thirdly, the teaching function of the teacher was replaced by electronic visualization and remote control, transferred to a greater extent to their parents (who are far from professional teachers), which also was not efficient [18]. The problems that have been identified by scientists and teachers from different countries at the level of secondary education require careful study and a cautious approach to the idea of digitalization of education at the level of university training.

\section{Conclusion}

At the moment, it is possible to formulate the main goal of higher education - as the formation of a specialist with a high level of professional consciousness, who knows specialized methods of activity and basic digital technologies for this type of activity. The introduction of digital education and training in computer technologies should be carried out in stages. At the initial stage of training in professional activity at the university, associated with the psychological "breaking" of the student's everyday consciousness and adjusting his thinking to a professional way $[10,14]$, digital technologies are more efficient in mastering in parallel in special disciplines that do not require complex creative solutions. At the second stage, when there is a transition to specialized disciplines, computer technologies should be integrated into these disciplines so that the stage of materialization of mental actions (in the form of sketches, schemes, etc.) is preserved. At senior courses, when there is a stabilization of professional thinking and "vision" of students, digital teaching methods can acquire be used in a more extensive way. Here it is important to preserve the possibility of direct communication, "live" communication between the professor and the student, which is an important condition for rapid postgraduate adaptation of students at specialized enterprises $[16,19]$.

The training of future specialists in creative specializations will be more efficient if we do not discount the psychological features of professional training, as well as if digital technologies will complement the training and not replace the professor. In this context, digital technologies and distance education can and should be applied as forms that complement traditional forms of learning but do not replace them. The first stages of training at the university are especially important since they lay the foundations of 
professional "vision" and thinking, require the direct participation of the professor in the student's activities and careful monitoring of all the nuances of the formation of his consciousness. Just as a well-laid foundation provides a home with durability and reliability, so a well-formed professional thinking and "vision" of a future specialist create the basis for a high-quality and high-level training. It is also important to take into account the fact that the professor's profession is creative, requires a certain freedom of action, which is associated with his ability to understand and take into account psychology, to find an approach to each student, and communication between the professor and the student is one of the most important factors affecting the success of the educational process. Computer technologies help the learning process at the university and contribute to its acceleration only when the basic foundations of professional thinking and activity of students have already been formed.

\section{References}

1. R. Arnheim, Art and Visual Perception (2007)

2. R.L. Gregory, The Intelligent Eye (1972)

3. D. Hubel, Eye, Brain, Vision (1990)

4. V.D. Glezer, Vision and Thinking (1993)

5. V.P. Zinchenko, N.Yu. Vergiles. Formation of Visual Image (study of the visual system activity) (1969)

6. V.V. Davydov, Theory of Developmental Learning (1996)

7. A.N. Leontiev, Activity. Conscience. Personality (2005)

8. P.Ya. Galperin, Psychology as an Objective Science: Selected Psychological Works (1998)

9. V.P. Zinchenko, Psychology of Education: Textbook (2018)

10. N.N. Nechaev, Psychological and Pedagogical Foundations for the Formation of Professional Activity: Textbook (1988)

11. L.S. Vygotsky, Psychology of Human Development: Textbook (2005)

12. P.Ya. Galperin, Bulletin of the Moscow University, Experience of Studying the Formation of Mental Actions: Report, 4, 6 (2017)

13. N.N. Nechaev, Mathematical Psychology: School of V.Yu. Krylov (2010)

14. N.N. Nechaev, Psychology. Selected Psychological Works (2014)

15. M.O. Surina, A.A. Surin. History of Education and Color Didactics (2003)

16. A.A. Surin, M.O. Surina, S.Ya. Gagen, Methodological-Theoretical and Technological Resource for the Development of the Information and Educational Environment: Collection of Articles, 9, 367 (2018)

17. N.N. Nechaev, A.I. Rud, A.V. Skopintsev, Computer Technologies and Architectural Creativity: Textbook (1990)

18. Materials of the First Meeting of the International Round Table on Digital Education, https://www.youtube.com/

19. M.M. Simonova, Problems of Modern Education, 1, 9 (2019) 